\title{
A Statistical Cyclone Intensity Prediction (SCIP) model for the Bay of Bengal
}

\author{
S D Kotal ${ }^{1}$, S K Roy Bhowmik ${ }^{1}$, P K Kundu ${ }^{2}$ and Ananda Kumar Das ${ }^{1}$ \\ ${ }^{1}$ India Meteorological Department, New Delhi 110 003, India. \\ ${ }^{2}$ Department of Mathematics, Jadavpur University, Kolkata 700 032, India.
}

\begin{abstract}
A statistical model for predicting the intensity of tropical cyclones in the Bay of Bengal has been proposed. The model is developed applying multiple linear regression technique. The model parameters are determined from the database of 62 cyclones that developed over the Bay of Bengal during the period 1981-2000. The parameters selected as predictors are: initial storm intensity, intensity changes during past 12 hours, storm motion speed, initial storm latitude position, vertical wind shear averaged along the storm track, vorticity at $850 \mathrm{hPa}$, Divergence at $200 \mathrm{hPa}$ and sea surface temperature (SST). When the model is tested with the dependent samples of 62 cyclones, the forecast skill of the model for forecasts up to 72 hours is found to be reasonably good. The average absolute errors (AAE) are less than 10 knots for forecasts up to 36 hours and maximum forecast error of order 14 knots occurs at 60 hours and 72 hours. When the model is tested with the independent samples of 15 cyclones (during 2000 to 2007), the AAE is found to be less than 13 knots (ranging from 5.1 to 12.5 knots) for forecast up to 72 hours. The model is found to be superior to the empirical model proposed by Roy Bhowmik et al (2007) for the Bay of Bengal.
\end{abstract}

\section{Introduction}

Tropical cyclones are well known for their destructive character and impact on human activities. Three elements associated with a cyclone which cause destruction, are heavy and prolonged rain, storm surge and very strong winds. In tropical countries like India, where thick population exists along the large segments of the coasts, it is one of the most disastrous events. The super cyclone of Orissa (1999) was the most severe cyclone during recent times that India experienced with wind speed exceeding $250 \mathrm{~km}$ per hour. The massive destruction caused by winds, surge and torrential rains resulted in the collapse of nearly 4 lakh houses, damage of a total of 19 lakh houses, affected more than 25 lakh people, took a toll of nearly 10,000 human lives and left many people injured. The coastal districts counted a death toll of more than 8000 lives mainly because of storm surge (Kalsi 2005). This devastating cyclone illustrates the need for accurate prediction of tropical cyclone intensity.

The Northern Hemisphere Analysis Centre (NHAC) at the Head Quarter (HQ) of India Meteorological Department (IMD) functions as a Regional Specialized Meteorological Centre (RSMC) for tropical cyclone, as recognized by the World Meteorological Organization (WMO). According to WMO's Tropical Cyclone Programme (TCP), one of the major responsibilities of RSMC, New Delhi is to provide tropical cyclone advisories to the member countries with regard to cyclones in the north Indian seas, apart from its national responsibilities of co-ordination and supervision of the totality of cyclone warning programs in India. Cyclone advise for the member countries, which begins from the cyclone stage, includes information related to present and forecast track and intensity.

Though with the availability of sophisticated Numerical Weather Prediction (NWP) models some progress has been made in tropical cyclone

Keywords. Tropical cyclone; intensity prediction; multiple linear regression; regression coefficient; statistical model. 
track prediction, the skill of intensity prediction is still very much lacking for operational application (Elsberry et al 2007 and Houze et al 2007). However, the HWRF (Hurricane Weather Research and Forecast) model developed by National Centre for Environmental Prediction (NCEP) is expected to be promising in this front, but the model is still under research and in an experimental mode. Until the time NWP models can be used with reasonable success, there is an imperative need in the operational scenario to use statistical or empirical models for predicting the intensity of tropical cyclones.

In this context, few statistical models have been found promising to address the problem of operational forecasting of tropical cyclone intensity (Jarvinen et al 1979; DeMaria and Kaplan 1994, 1999; Fitzpatrick 1997; Hobgood 1998; Baik and Hwang 1998). For intensity up to 72 hours, the SHIFOR (Statistical Hurricane Intensity Forecast) model (Jarvinen and Neumann 1979), which is based on climatology and persistence, is most commonly used in the Atlantic basin. The SHIPS (Statistical Hurricane Intensity Prediction System) model (DeMaria and Kaplan 1994, 1999) predicts intensity up to 72 hours in the Atlantic basin and in the eastern north Pacific basin. This model uses climatology, persistence and synoptic predictors. Like SHIPS model, the TIPS (Typhoon Intensity Prediction System) model (Fitzpatrick 1997) predicts intensity up to 48 hours over the western north Pacific Ocean. The model includes digitized satellite data as predictors. A similar statistical model (Hobgood 1998) was also developed for eastern north Pacific Ocean using climatology and persistence.

Though such statistical models are available for the Atlantic, eastern north Pacific and western north Pacific basins, no such model is presently available for the Indian seas for predicting the intensity of tropical cyclones. Due to nonavailability of such objective methods in the operational scenario, a more subjective approach combining the inputs of persistency, climatology, synoptic and satellite technique would be a primary aid for the forecast of tropical cyclone intensity over the north Indian sea.

Very recently, Roy Bhowmik et al (2007) proposed a simple empirical model for predicting the intensity of tropical cyclones for the Bay of Bengal. The study is based on the assumption that tropical cyclones intensify exponentially, where the intensification factor is determined using the previous 12 hours intensity changes. A major limitation of this empirical model (Roy Bhowmik et al 2007) is that it does not include parameters to take into account the physical and dynamical processes involved. The study warranted further investigation in a more general manner incorporating other synoptic and thermodynamic factors, which play an important role for the intensification of storms.

Towards this direction, an attempt has been made in this paper to derive a statistical model for predicting 12-hourly tropical cyclone intensity (up to 72 hours), applying multiple linear regression technique using various dynamical and physical parameters as predictors. This model takes into account the decaying features of storm on the basis of predictors namely, the previous 12 hours change in the intensity, vorticity, divergence and vertical wind shear. The study considers a database of 62 cyclones over the Bay of Bengal. The model is tested with the dependent sample of 62 cyclones as well as the independent sample of recently occurred 15 cyclones over the Bay of Bengal during the period 2000-2007.

The source of data sample is described in section 2. The model parameters and formulation of the model are described in sections 3 and 4 respectively. Performance of the model is discussed in section 5 and concluding remarks are given in section 6 .

\section{Data sources}

The sample database of 62 cyclones used for the formulation of the model is shown in table 1 . These cyclones formed over the Bay of Bengal during the period 1981-2000. As per the convention of India Meteorological Department (IMD), the classification of tropical disturbances is as follows:

- low - wind speed less than 17 knots,

- depression - wind speed of 17-33 knots,

- cyclonic storm - wind speed of 34-47 knots,

- severe cyclonic storm - wind speed of 48-63 knots,

- very severe cyclonic storm - wind speed of 64-119 knots; and

- super cyclone - wind speed above 119 knots.

The cyclone Atlas of IMD contains only 03 UTC and 12 UTC track positions and intensities. IMD, New Delhi started functioning as RSMC from the year 1990. The 3-hourly position and intensity of cyclones are available in the IMD's RSMC report from the year 1990. In view of this, cyclone data such as intensity, track, etc., obtained from the Joint Typhoon Warning Center (JTWC) "best track" database (Chu et al 2002) from 1981 are used in developing the SCIP model. The data table includes date and time, position in latitude and longitude and intensity (maximum sustained surface winds in knots). The maximum sustained surface wind of a tropical cyclone is 
Table 1. The 62 cyclones considered for the study.

\begin{tabular}{|c|c|c|c|}
\hline Period & Year & $\begin{array}{c}\text { Max. wind } \\
\text { speed (knots) }\end{array}$ & Coast of landfall \\
\hline 17-20 November & 1981 & 75 & Bangladesh \\
\hline 5-10 December & 1981 & 75 & Bangladesh \\
\hline 30 April-5 May & 1982 & 120 & Myanmar \\
\hline 30 May-2 June & 1982 & 55 & Orissa \\
\hline 13-16 October & 1982 & 50 & Andhra Pradesh \\
\hline 17-19 October & 1982 & 50 & Andhra Pradesh \\
\hline 1-4 October & 1983 & 50 & Andhra Pradesh \\
\hline 5-9 November & 1983 & 55 & Bangladesh \\
\hline 10-14 October & 1984 & 45 & Orissa-West Bengal \\
\hline 9-15 November & 1984 & 85 & Andhra Pradesh \\
\hline 27 November-8 December & 1984 & 75 & Tamil Nadu \\
\hline 22-25 May & 1985 & 60 & Bangladesh \\
\hline 8-11 October & 1985 & 50 & Andhra Pradesh \\
\hline 13-18 November & 1985 & 55 & Andhra Pradesh \\
\hline 9-14 December & 1985 & 50 & Andhra Pradesh \\
\hline 15-16 October & 1985 & 50 & Orissa \\
\hline 7-11 January & 1986 & 45 & Weakened \\
\hline 30 January-4 February & 1987 & 55 & Myanmar \\
\hline 30 May-5 June & 1987 & 55 & Bangladesh \\
\hline 14-16 October & 1987 & 40 & Andhra Pradesh \\
\hline 30 October-3 November & 1987 & 55 & Andhra Pradesh \\
\hline 8-13 November & 1987 & 55 & Andhra Pradesh \\
\hline 17-23 December & 1987 & 35 & Tamil Nadu \\
\hline 14-18 November & 1988 & 55 & Myanmar \\
\hline 21-30 November & 1988 & 110 & Indo-Bangla Border \\
\hline 6-8 December & 1988 & 40 & Weakened \\
\hline 23-27 May & 1989 & 55 & West Bengal \\
\hline 3-11 May & 1990 & 100 & Andhra Pradesh \\
\hline 13-19 December & 1990 & 45 & Bangladesh-Myanmar \\
\hline 17-18 April & 1990 & 25 & Weakened \\
\hline 30 October-14 November & 1990 & 30 & Andhra Pradesh \\
\hline 22-30 April & 1991 & 140 & Bangladesh \\
\hline 30 May-3 June & 1991 & 50 & Bangladesh \\
\hline 9-16 November & 1991 & 40 & Tamil Nadu \\
\hline 15-20 May & 1992 & 65 & Mayanmar \\
\hline 14-18 June & 1992 & 35 & Orissa \\
\hline 24-28 July & 1992 & 40 & Orissa \\
\hline $4-9$ October & 1992 & 45 & Andhra Pradesh \\
\hline 31 October-8 November & 1992 & 55 & Weakened \\
\hline 6-17 November & 1992 & 55 & Sri Lanka \\
\hline 13-22 October & 1992 & 30 & Bangladesh \\
\hline 27 November-5 December & 1993 & 75 & Tamil Nadu \\
\hline 18-25 March & 1994 & 40 & Weakened \\
\hline 26 April-3 May & 1994 & 125 & Bangladesh-Myanmar \\
\hline 28-31 October & 1994 & 45 & Tamil Nadu \\
\hline 5-10 November & 1995 & 70 & Andhra Pradesh \\
\hline 18-25 November & 1995 & 105 & Bangladesh \\
\hline 1-8 May & 1996 & 40 & Bangladesh-Myanmar \\
\hline 11-18 June & 1996 & 45 & Andhra Pradesh \\
\hline 21-29 October & 1996 & 45 & Bangladesh \\
\hline 1-7 November & 1996 & 115 & Andhra Pradesh \\
\hline 26 November-7 December & 1996 & 75 & Tamil Nadu \\
\hline
\end{tabular}


Table 1. (Continued).

\begin{tabular}{lccl}
\hline Period & Year & $\begin{array}{c}\text { Max. wind } \\
\text { speed (knots) }\end{array}$ & \multicolumn{1}{c}{ Coast of landfall } \\
\hline 14 October-2 November & 1996 & 20 & Tamil Nadu \\
13-20 May & 1997 & 115 & Bangladesh \\
19-27 September & 1997 & 65 & Bangladesh \\
13-20 May & 1998 & 70 & Bangladesh \\
13-16 November & 1998 & 85 & Andhra Pradesh \\
16-23 November & 1998 & 70 & West Bengal \\
30 January-4 February & 1999 & 40 & Weakened \\
15-18 October & 1999 & 120 & Orissa \\
25 October-3 November & 1999 & 140 & Orissa \\
14-18 October & 2000 & 35 & Weakened \\
\hline
\end{tabular}

Table 2. The 15 cyclones considered for the validation.

\begin{tabular}{lccl}
\hline Period & Year & $\begin{array}{c}\text { Max. wind } \\
\text { speed (knots) }\end{array}$ & Coast of landfall \\
\hline $25-28$ October & 2000 & 35 & Bangladesh \\
26 November-6 December & 2000 & 65 & Tamil Nadu \\
23-28 December & 2000 & 65 & Sri Lanka \\
9-12 November & 2001 & 30 & Andhra Pradesh \\
9-12 November & 2002 & 45 & Myanmar \\
10-19 May & 2003 & 75 & Myanmar \\
11-16 December & 2003 & 55 & Machilipatnam \\
16-19 May & 2004 & 77 & Myanmar \\
13-17 January (HIBARU) & 2005 & 35 & Weakened \\
17-21 September (PYAAR) & 2005 & 35 & Andhra Pradesh \\
28 November-2 December (BAAZ) & 2005 & 45 & Weakened \\
6-10 December (FANOOS) & 2005 & 45 & Tamil Nadu \\
25-29 April (MALA) & 2006 & 100 & Arakan coast \\
29-30 October (OGNI) & 2006 & 35 & Andhra Pradesh \\
13-15 May (AKASH) & 2007 & 45 & Bangladesh \\
\hline
\end{tabular}

a common indicator of the intensity of a storm. According to the convention of Joint Typhoon Warning Center (JTWC), maximum sustained surface wind is the average winds over a period of one minute. In this study, knots is used instead of standard unit meters per second as winds are forecast in knots $\left(1 \mathrm{knot}=0.5144 \mathrm{~m} \mathrm{~s}^{-1}\right)$. Various thermo-dynamical parameters, which are used as predictors are derived from European Centre for Medium Range Weather Forecasting (ECMWF) ERA 40 reanalysis daily fields available at $2.5^{\circ}$ latitude-longitude grid. Sea surface temperature (Reynolds SST) is obtained from National Centre for Environmental Prediction (NCEP) reanalysis data, which are available at $1^{\circ}$ latitude-longitude grid (Reynolds et al 2002). These data are freely available through the Internet.

The model is tested for the fifteen cyclones over the Bay of Bengal during the period from 2000 to 2007. These cyclones are presented in table 2 . As ECMWF (ERA-40) reanalysis data are available freely through the Internet up to August 2002, for this exercise NCEP (National Center for Environmental Prediction) reanalysis data has been used after August 2002 available at $2.5^{\circ}$ latitudelongitude grid to derive the thermo-dynamical predictors. The data of track position and intensity of cyclones are obtained from IMD's RSMC report. According to the new convention of WMO, cyclones are assigned a name from 2005, which is indicated in table 2 .

\section{The predictors}

The importance of ocean, inner core process and environmental interactions on tropical cyclone intensity change has been discussed by many authors 
Table 3. Model parameters.

\begin{tabular}{lll}
\hline Predictors & $\begin{array}{l}\text { Symbol of } \\
\text { predictors }\end{array}$ & \multicolumn{1}{c}{ Unit } \\
\hline Intensity change during last 12 hours & IC12 & Knots \\
Vorticity at $850 \mathrm{hPa}$ & $\mathrm{V} 850$ & $\times 10^{5} \mathrm{~s}^{-1}$ \\
Storm motion speed & $\mathrm{SMS}$ & $\mathrm{m} \mathrm{s}^{-1}$ \\
Divergence at $200 \mathrm{hPa}$ & $\mathrm{D} 200$ & $\times 10^{5} \mathrm{~s}^{-1}$ \\
Initial storm intensity & $\mathrm{ISI}$ & $\mathrm{Knots}$ \\
Initial storm latitude position & $\mathrm{ISL}$ & ${ }^{\circ} \mathrm{N}$ \\
Sea surface temperature & $\mathrm{SST}$ & ${ }^{\circ} \mathrm{C}$ \\
Vertical wind shear & $\mathrm{VWS}$ & $\mathrm{Knots}$ \\
\hline
\end{tabular}

Table 4. Normalized regression coefficients of predictors; $(*)$ marks indicate significant at $95 \%$ level $\left(R^{2}=\right.$ per cent of variance explained by multiple linear regression; $N=$ number of samples).

\begin{tabular}{lcccccc}
\hline & \multicolumn{5}{c}{ Forecast interval } \\
\cline { 2 - 7 } Predictors & $12 \mathrm{hr}$ & $24 \mathrm{hr}$ & $36 \mathrm{hr}$ & $48 \mathrm{hr}$ & $60 \mathrm{hr}$ & $72 \mathrm{hr}$ \\
\hline IC12 & $0.29^{*}$ & $0.27^{*}$ & $0.18^{*}$ & $0.12^{*}$ & 0.07 & 0.04 \\
V850 & $0.19^{*}$ & $0.22^{*}$ & $0.25^{*}$ & $0.26^{*}$ & $0.25^{*}$ & $0.23^{*}$ \\
SMS & $0.15^{*}$ & $0.17^{*}$ & $0.25^{*}$ & $0.31^{*}$ & $0.34^{*}$ & $0.37^{*}$ \\
D200 & $0.11^{*}$ & $0.13^{*}$ & $0.15^{*}$ & $0.18^{*}$ & $0.15^{*}$ & $0.19^{*}$ \\
ISI & 0.09 & $0.15^{*}$ & $0.14^{*}$ & 0.03 & 0.05 & 0.01 \\
ISL & 0.09 & $0.15^{*}$ & $0.22^{*}$ & $0.29^{*}$ & $0.29^{*}$ & $0.29^{*}$ \\
SST & $0.11^{*}$ & $0.09^{*}$ & -0.01 & -0.04 & -0.05 & $-0.09^{*}$ \\
VWS & $-0.18^{*}$ & $-0.29^{*}$ & $-0.32^{*}$ & $-0.33^{*}$ & $-0.31^{*}$ & $-0.28^{*}$ \\
$\mathrm{R}^{2}(\%)$ & 28 & 35 & 34 & 32 & 27 & 26 \\
$\mathrm{~N}$ & 415 & 353 & 291 & 232 & 175 & 123 \\
\hline
\end{tabular}

(Fitzpatrick 1997; Emanuel 1999; Schade and Emanuel 1999; Kaplan and DeMaria 2003, etc.). The statistical model SHIPS (DeMaria et al 1994, 1999) combines climatology, persistence and synoptic predictors (such as information related to SST, vertical wind shear, upper tropospheric trough, etc.) using multiple regression equation. In the updated version of SHIPS (DeMaria and Kaplan 1999), analysis and forecast fields from the NWP model are used for deriving synoptic predictors.

The predictors selected for the present model are discussed below:

\section{(a) Persistence factors}

Roy Bhowmik et al (2007) showed that tropical cyclones over the Bay of Bengal intensify exponentially, and intensity at any time depends upon the initial intensity and previous 12 hours changes in the intensity. In view of this, two parameters selected to account for the persistence are:

(i) Initial storm intensity (ISI)

(ii) Previous 12 hours change in the intensity (IC12) (b) Thermodynamical factors

Two thermodynamical parameters selected as predictors are:

(i) Storm motion speed (SMS)

(ii) Sea surface temperature (SST)

(c) Dynamical factors

Four dynamical parameters considered as predictors are:

(i) Initial storm latitude position (ISL)

(ii) Vertical wind shear (850-200) hPa averaged along storm track (VWS)

(iii) Vorticity at $850 \mathrm{hPa}$ (V850)

(iv) Divergence at $200 \mathrm{hPa}$ (D200)

The selected predictors have certain physical significance with the future change of intensity. These predictors are statistically significant (exceeding 95\% confidence level). Standard F-statistic was used to test the significance level of each regression coefficient.

Comparison of regression coefficient between different predictors for different forecast hours is made by normalizing regression coefficients 
Table 5. Regression coefficients for different forecasts hours.

\begin{tabular}{|c|c|c|c|c|c|c|c|c|c|}
\hline $\begin{array}{l}\text { Forecast } \\
\text { hours }\end{array}$ & $a_{0}$ & $a_{1}$ & $a_{2}$ & $a_{3}$ & $a_{4}$ & $a_{5}$ & $a_{6}$ & $a_{7}$ & $a_{8}$ \\
\hline $12 \mathrm{hr}$ & -9.54983 & 0.31517 & 0.6749 & -0.18668 & 0.865 & 0.75918 & 0.16853 & 0.24186 & 0.04103 \\
\hline $24 \mathrm{hr}$ & -14.66671 & 0.58485 & 1.42963 & -0.54507 & 1.58903 & 1.46658 & 0.5017 & 0.36094 & 0.14683 \\
\hline $36 \mathrm{hr}$ & -7.61006 & 0.57747 & 3.03779 & -0.8867 & 2.51223 & 2.28032 & 1.02698 & -0.072297 & 0.22346 \\
\hline $48 \mathrm{hr}$ & 4.4943 & 0.54152 & 5.0484 & -1.18528 & 3.29409 & 2.63681 & 1.66914 & -0.71783 & 0.3127 \\
\hline $60 \mathrm{hr}$ & 18.75396 & 0.37624 & 6.66114 & -1.33578 & 3.14652 & 2.85734 & 1.95777 & -1.08646 & 0.1684 \\
\hline $72 \mathrm{hr}$ & 24.58879 & 0.19425 & 7.87951 & -1.31717 & 5.09006 & 2.49177 & 2.22359 & -1.30808 & 0.10789 \\
\hline
\end{tabular}

(DeMaria and Kaplan 1994). In other words, the normalized regression coefficients are compared to judge relative predictive power of independent variables. The predictors and normalized regression coefficient of each variable are listed in tables 3 and 4 respectively. Before regression analysis, each dependent and independent variable is normalized by subtracting their mean and dividing by their standard deviation. Table 4 shows that predictors namely, ISI, IC12, SMS, ISL, V850 and D200 are positively correlated and the predictor VWS is negatively correlated at all the forecast intervals. The predictor SST is found to be positively correlated up to 24 hours forecast.

Storm motion speed (SMS) from the initial position to the final forecast hour position is one of the most significant parameters among the 8 parameters when all the regressions are considered. SMS is positively correlated with the intensity change. A slow-moving storm shows slow intensification, probably due to the fact that sea surface temperature (SST) gets cool easily for a slow moving or stationary system (Geisler 1970). In view of this, SMS is included among the thermodynamic factors.

Vertical wind shear (VWS) is estimated by taking vector difference between $200 \mathrm{hPa}$ and $850 \mathrm{hPa}$, averaged over an area of radius $2.5^{\circ}$ on the storm center. To take into account the time variation, the vertical wind shear is taken as the average of the magnitudes for each 12-hour position along the storm track (DeMaria and Kaplan 1994). Vertical wind shear is the second most significant parameter, which is negatively correlated with the intensity changes. Negative correlation justifies its physical reason as the higher vertical wind shear disrupts the circulation pattern and latent heat released within the system due to condensation advected away from the system. Initial storm latitude position (ISL) is found to be positively correlated.

Vorticity at $850 \mathrm{hPa}$, divergence at $200 \mathrm{hPa}$ are calculated by averaging over an area of radius $2.5^{\circ}$ on the storm center using analysis parameters. Vorticity at $850 \mathrm{hPa}$ and divergence at $200 \mathrm{hPa}$ are positively correlated which has physical significance as more cyclonic environment at $850 \mathrm{hPa}$ and more anticyclonic environment at $200 \mathrm{hPa}$ are favourable conditions for intensification. These two coefficients are also the most stable coefficients during all forecast periods, which maintained almost the same significance for all forecast hours.

Intensity changes are positively correlated with initial storm intensity (ISI). The coefficients of intensity change during the previous 12 hours (IC12) are positive and decrease with the higher forecast period. Positive coefficient shows that intensity changes during the previous 12 hours can indicate the future rate of intensification. If intensity increases in the previous 12 hours, the same environmental condition is likely to prevail for shorter intervals. The decrease of coefficients for higher forecast periods indicates that there is less probability that the same environmental condition is likely to prevail for higher forecast periods. Sea Surface Temperature (SST) becomes negatively correlated from 36 to 72 hours. The negative coefficient may be due to the fact that SST decreases towards the higher latitudes. Moreover, during the later hours SST may become cooler due to reduction in incoming solar radiation, enhanced evaporation and mixing with the colder water from below the mixed layer. This apparently does not affect the intensification process, as SST remains higher than the threshold value of $26.5^{\circ} \mathrm{C}$ for intensification over the Bay of Bengal.

\section{Formulation of the model}

The model is developed using multiple linear regression technique

$$
y=a_{0}+a_{1} x_{1}+a_{2} x_{2}+\cdots+a_{n} x_{n}
$$

where $y$ is the dependent variable (predictant) and $x_{1}, x_{2}, \ldots, x_{n}$ are independent variables (predictors). The regression coefficients $a_{1}, a_{2}, \ldots, a_{n}$ are 

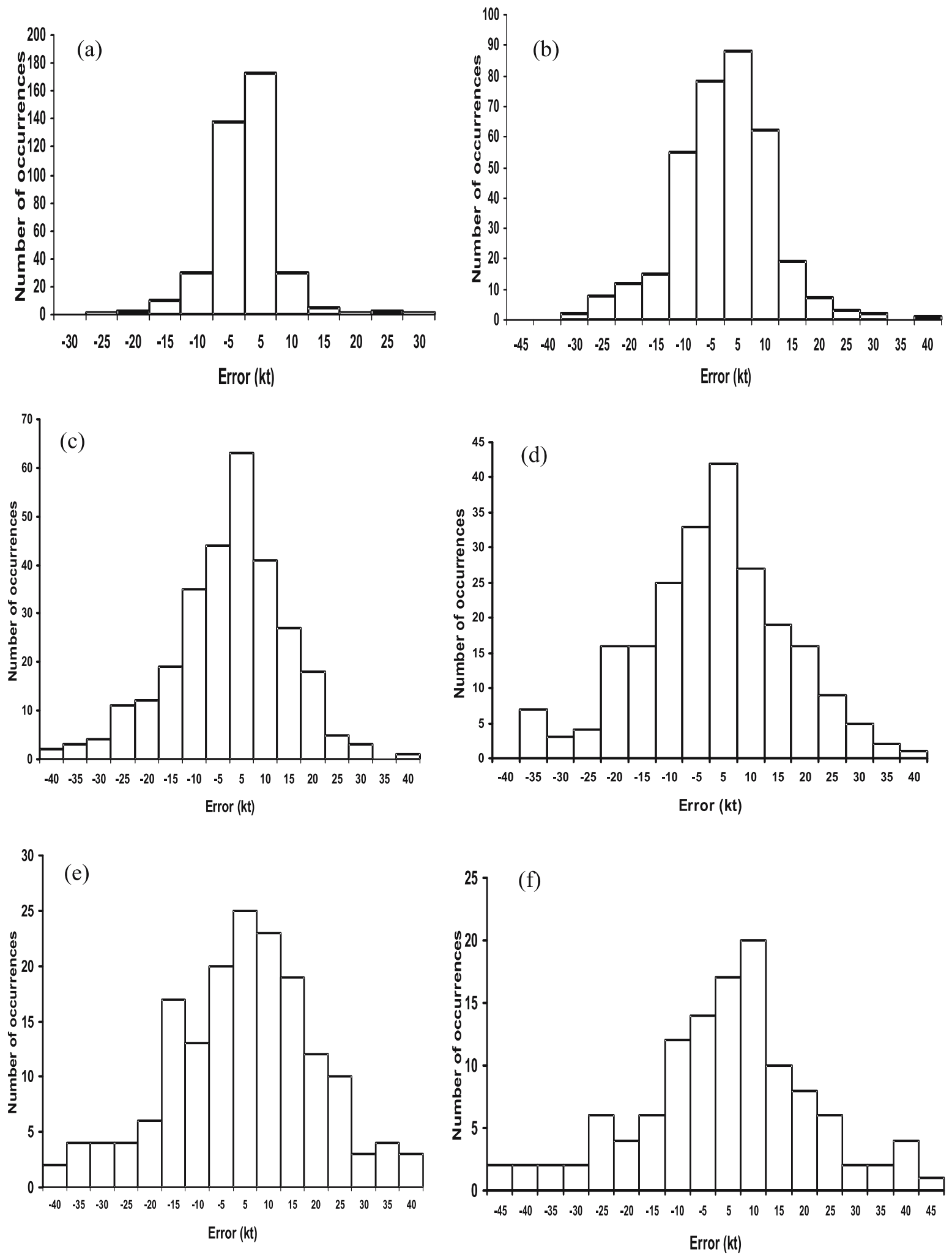

Figure 1. Frequency distributions of forecast errors (knots) for dependent samples: (a) for 12 hours, (b) for 24 hours, (c) for 36 hours, (d) for 48 hours, (e) for 60 hours and (f) for 72 hours forecast.

determined using a large data set (62 cyclones) and a statistical software package.

The SCIP model estimates changes of intensity at $12,24,36,48,60$ and 72 hours. Six separate regression analyses are carried out for forecast interval 12, 24, 36, 48, 60 and 72 hours.

Twelve hours intensity change by multiple linear regression technique is defined as: 


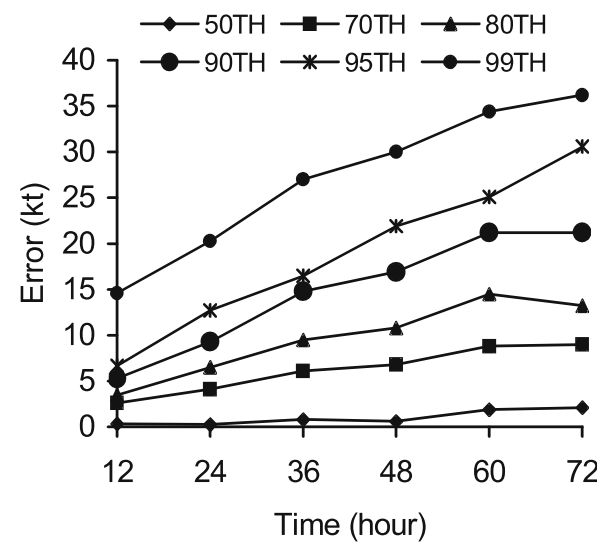

Figure 2. Percentiles of error distributions for dependent samples of the 62 cyclones considered in the study.

Table 6. Skill scores (AAE and RMSE in knots) of 12-hourly forecasts made for the 62 cyclones.

\begin{tabular}{lccrccc}
\hline & \multicolumn{6}{c}{ Forecast hours } \\
\cline { 2 - 7 } Skill & $12 \mathrm{hr}$ & $24 \mathrm{hr}$ & $36 \mathrm{hr}$ & $48 \mathrm{hr}$ & $60 \mathrm{hr}$ & $72 \mathrm{hr}$ \\
\hline AAE & 3.8 & 6.7 & 9.4 & 11.7 & 13.7 & 14.1 \\
RMSE & 5.6 & 9.2 & 12.7 & 15.7 & 18.0 & 19.1 \\
\hline
\end{tabular}

$$
\begin{aligned}
d v_{t}= & a_{0}+a_{1} \mathrm{IC} 12+a_{2} \mathrm{SMS}+a_{3} \mathrm{VWS}+a_{4} \mathrm{D} 200 \\
& +a_{5} \mathrm{~V} 850+a_{6} \mathrm{ISL}+a_{7} \mathrm{SST}+a_{8} \mathrm{ISI}
\end{aligned}
$$

for $t=$ forecast hour $12,24,36,48,60$ and 72 .

The dependent variable $d v$ (intensity changes) in knots, IC12 in knots, V850 in the units of $\times 10^{5} \mathrm{~s}^{-1}$, SMS in $\mathrm{m} \mathrm{s}^{-1}$, D200 in the units of $\times 10^{5} \mathrm{~s}^{-1}$, ISI in knots, SST in ${ }^{\circ} \mathrm{C}$ and VWS in knots.

The constant term $a_{0}$ and coefficients $a_{1}, a_{2}, \ldots, a_{8}$ for 12 -hourly forecast intervals are given in table 5 .

The normalized regression coefficients of five significant predictors namely ISL, SMS, VWS, D200 and V850 for different forecast hours are shown in table 4. It reveals that among the five predictors, ISL and SMS increase with forecast hours. This suggests that the intensity changes at higher forecast hours are more sensitive to ISL and SMS. Whereas the contribution of VWS, D200 and V850 in the intensity remains constant till 72 hours. Their signs are also consistent for all forecast hours.

The purpose of the present study is to demonstrate the potential of the statistical technique with the use of reanalysis data of (ERA 40) to predict cyclone intensity. It may be presumed that reanalysis data of (ERA 40) is superior to corresponding forecast fields. In this paper, the reanalysis data are used to achieve the optimum regression co-efficients.

\section{Performance of the model}

The performance of the model is tested using dependent samples of 62 cyclones as well as independent samples of 15 cyclones.

\subsection{For dependent samples}

\section{1.a Error distributions}

Figure $1(\mathrm{a}-\mathrm{f})$ shows the error distribution of forecasts for 12 hours to 72 hours. Figure 1(a) shows that at 12 hours, forecast error is 0 to $(+$ or -$)$ 5 knots in $75 \%$ occasions and $(+$ or -$) 5$ to $(+$ or -$) 10$ knots in $14 \%$ occasions. Figure $1(\mathrm{~b})$ shows that at 24 hours, forecast error is 0 to $(+$ or -$) 5$ knots in $47 \%$ occasions and $(+$ or -$) 5$ to $(+$ or -$) 10$ knots in $33 \%$ occasions; at 36 hours forecasts (figure 1c) error is 0 to $(+$ or -$) 5$ knots in $37 \%$ occasions and $(+$ or -$) 5$ to $(+$ or -$) 10$ knots in $26 \%$ occasions and between $(+$ or -$) 10$ and $(+$ or -$) 15$ knots in $13 \%$ occasions. The error (figure $1 \mathrm{~d})$, at 48 hours becomes 0 to $(+$ or -$) 5$ knots in $32 \%$ cases, $(+$ or -$) 5$ to $(+$ or -$) 10$ knots in $22 \%$ cases and $(+$ or -$) 10$ to $(+$ or -$) 15$ knots in $15 \%$ cases. In case of 60 hours forecast (figure 1e), error is 0 to $(+$ or -$) 5$ knots in $26 \%$ cases, $(+$ or $-) 5$ to $(+$ or -$) 10$ knots in $21 \%$ cases and $(+$ or -$) 10$ to $(+$ or -$) 15$ knots in $21 \%$ cases. For 72 hours forecast (figure 1f), error becomes 0 to $(+$ or -$) 5$ knots in $25 \%$ occasions, $(+$ or -$) 5$ to $(+$ or -$) 10$ knots in $26 \%$ occasions and $(+$ or -$)$ 10 to $(+$ or -$) 15$ knots in $13 \%$ occasions.

\section{1.b Percentiles of error distributions}

Figure 2 shows 50th, 70th, 80th, 90th, 95th and 99th percentiles of error distributions. The $p$ th percentile is a value so that roughly $p \%$ of the data is smaller and $(100-p) \%$ of the data is larger. Errors are less than 10 knots up to 70 th percentile for all forecasts hours. The error distribution ranges from 4 to 13 knots for 80 th percentile, from 5 to 21 knots for 90 th percentile, from 7 to 31 knots for 95 th and from 15 to 36 knots for 99 th percentile.

\section{1.c Skill score}

Table 6 shows the error statistics of the model. The Average Absolute Error (AAE) is less than 10 knots (ranging from 4 to 9 knots) for forecasts up to 36 hours. The average absolute error increases with the forecast period and it ranges from 12 to 14 knots for 48 to 72 hours forecast. The root mean square error (RMSE) is less than 13 knots (ranging from 6 to 13 knots) for the forecasts up to 36 hours. It ranges from 16 to 19 knots for forecast hours from 48 to 72 hours. 


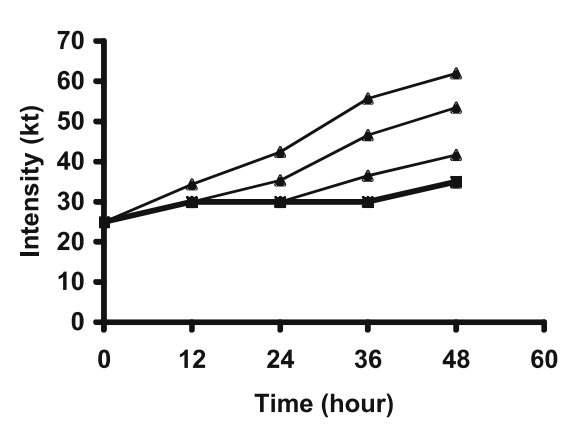

(a)

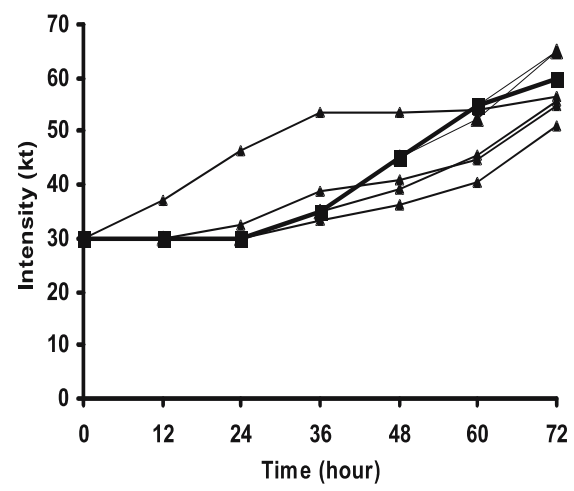

(c)

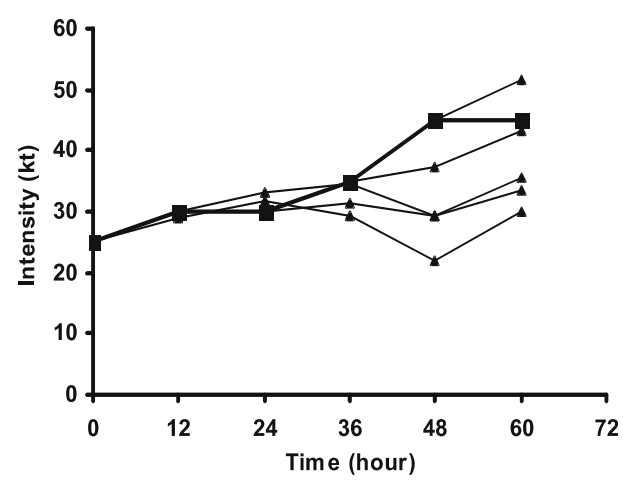

(e)

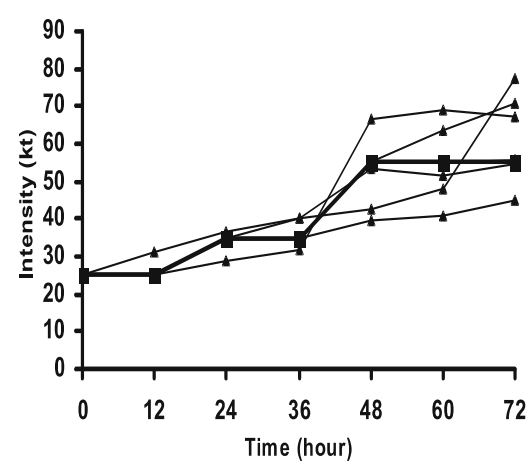

(g)

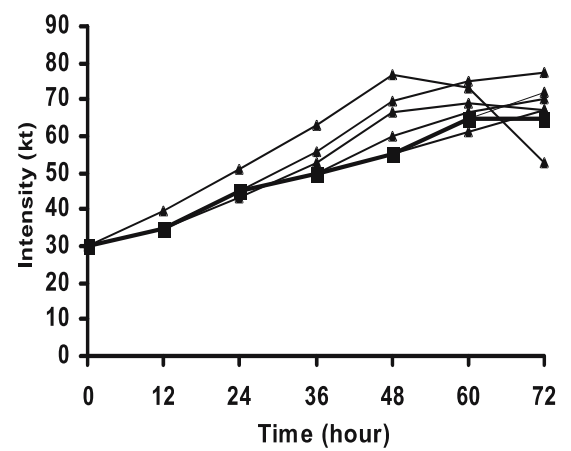

(b)

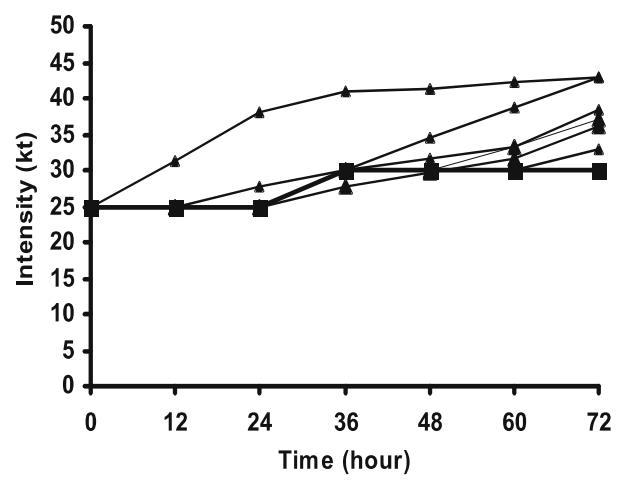

(d)

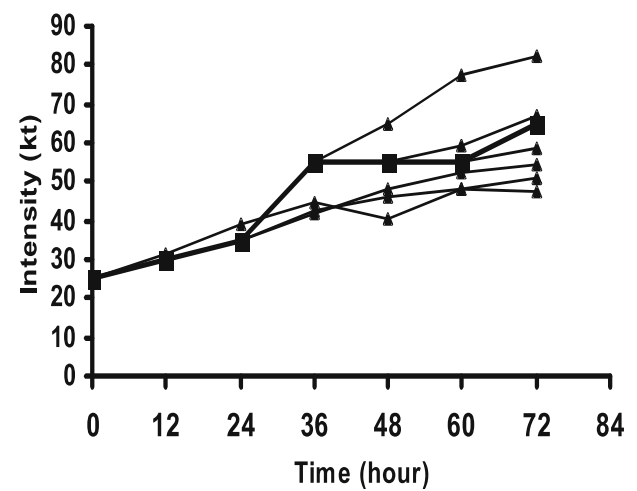

(f)

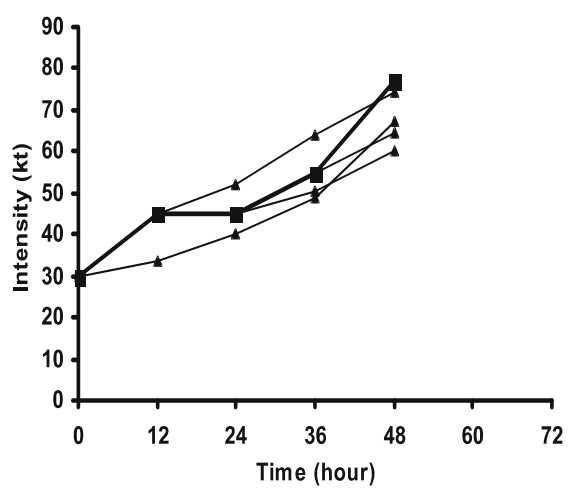

(h)

Figure 3. (Continued) 


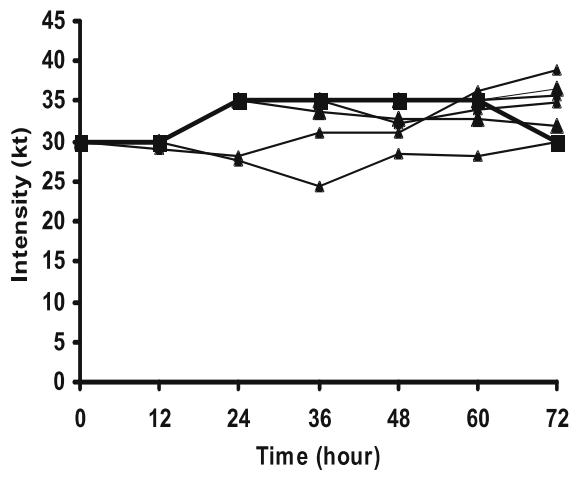

(i)

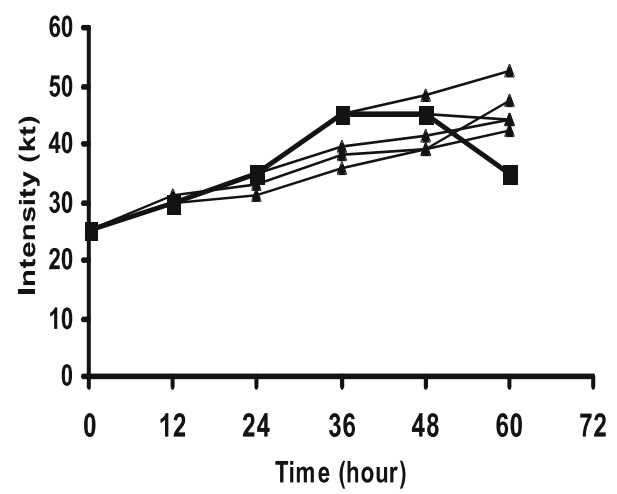

(k)

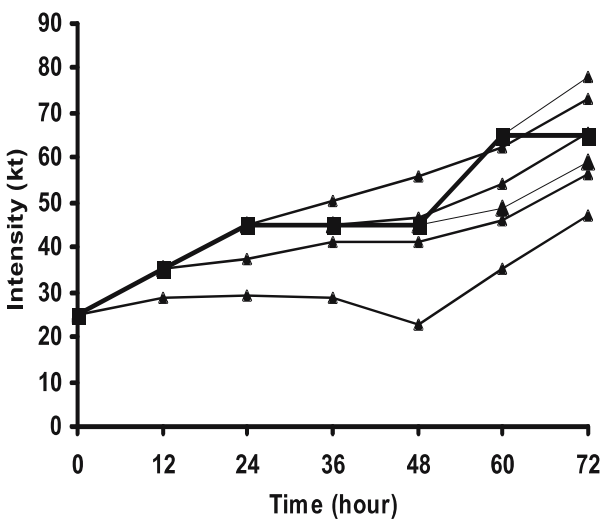

(m)

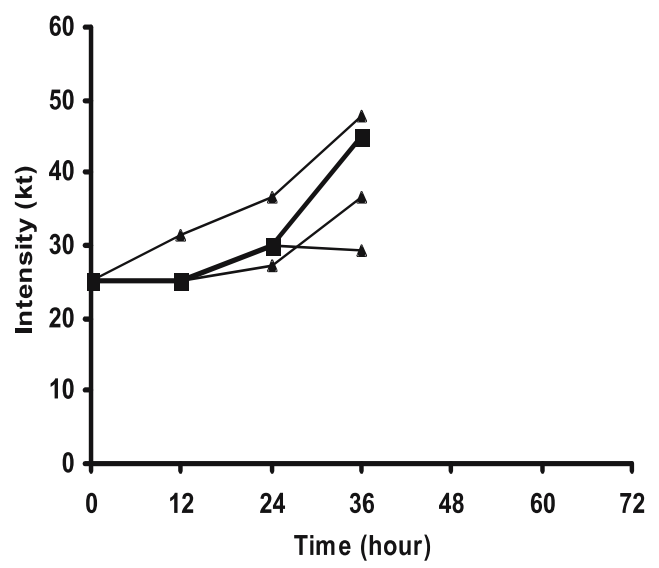

(o)

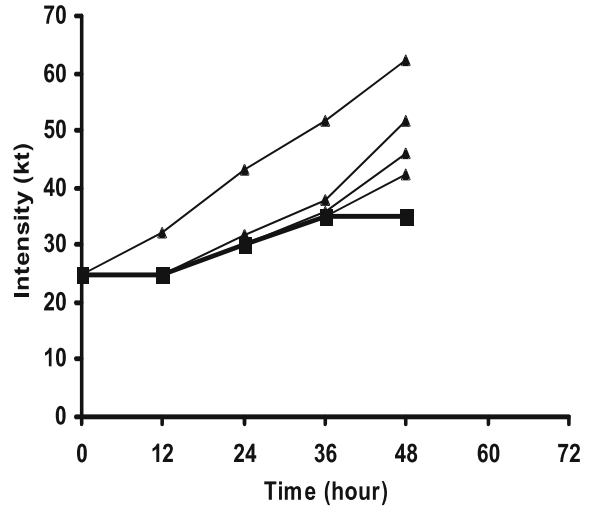

(j)

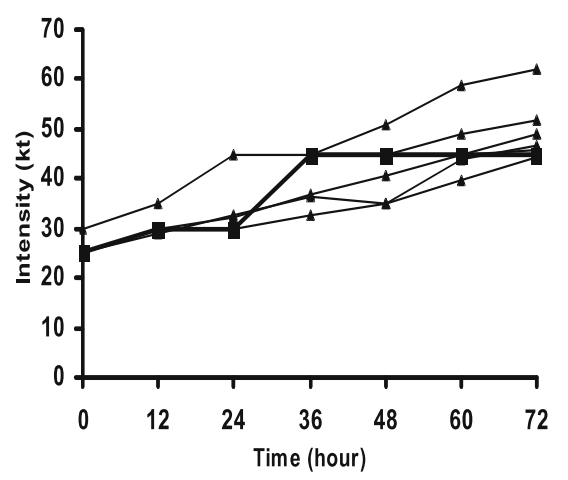

(1)

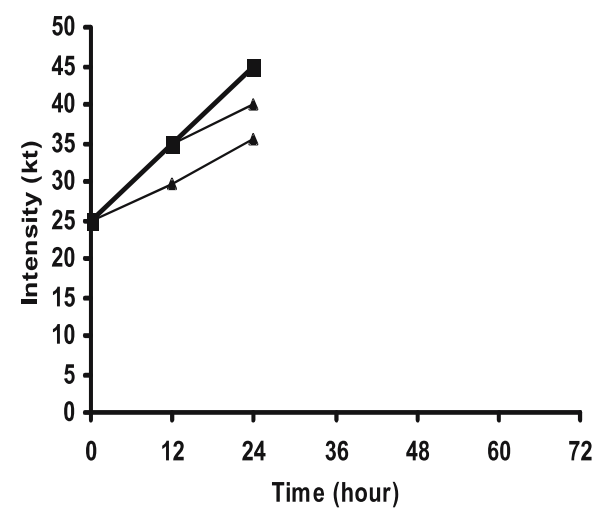

(n)

Figure $3(\mathrm{a}-\mathrm{O})$. The 12-hourly observed and forecasts intensities for fifteen independent cyclones. The observed intensity is indicated by thick line with solid squares and predicted intensity updated at different stages (12-hourly intervals) of the cyclones is indicated by thin lines with solid triangles. 


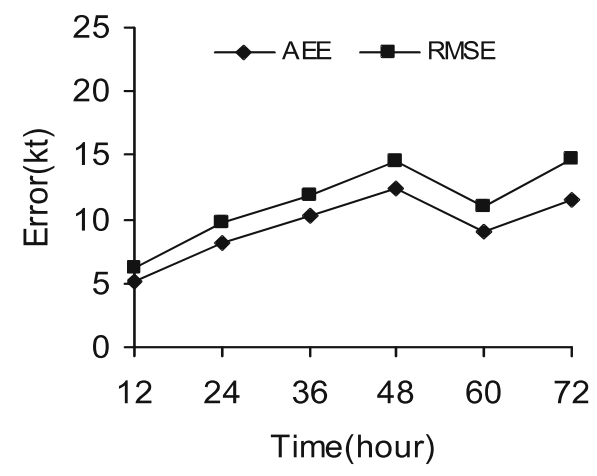

Figure 4. Average absolute error (AAE) and root mean square error (RMSE) as function of forecast hour for fifteen independent samples (during 2000-2007).

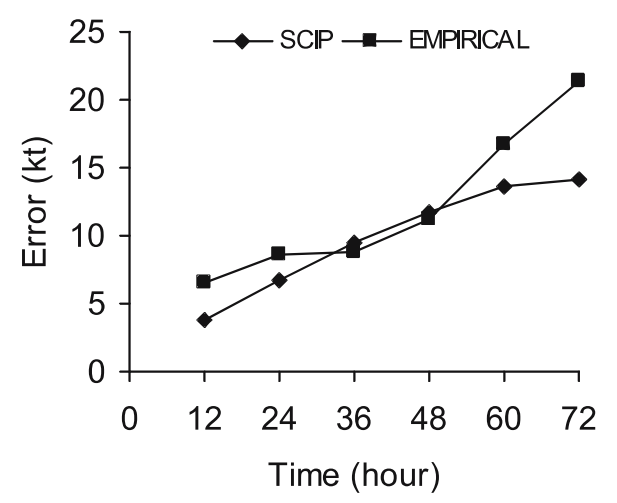

Figure 5. Average absolute errors for SCIP and empirical model proposed by Roy Bhowmik et al (2007).

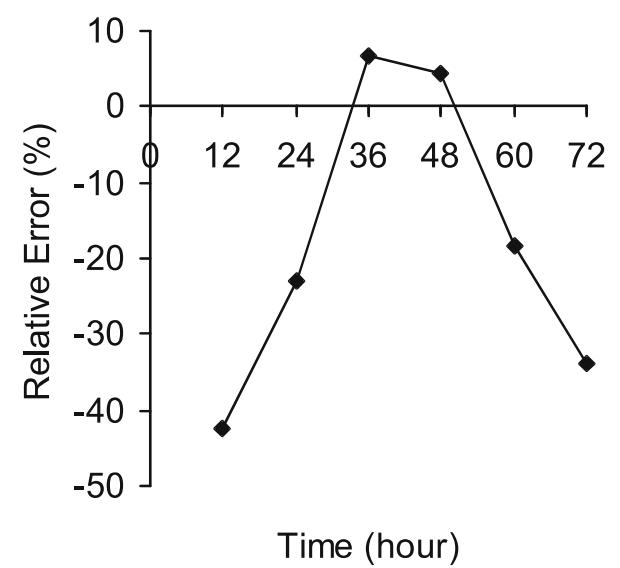

Figure 6. Relative errors for SCIP and empirical model proposed by Roy Bhowmik et al (2007).

\subsection{Independent samples for the cyclones of 2000-2007}

Model is tested for the fifteen cyclones over the Bay of Bengal during the period from 2000 to 2007. Figure $3(\mathrm{a}-\mathrm{O})$ illustrates the 12-hourly updated forecasts valid up to 72 hours for fifteen independent cyclones. Observed intensity is indicated by thick line with solid squares and predicted intensities by thin lines with solid triangles updated at different stages (12 hourly intervals) of cyclones. The AAE is found to be less than 13 knots (ranging from 5.1 to 12.5 knots) for forecasts up to 72 hours. The Root Mean Square Error (RMSE) is ranging from 6.2 to 14.8 knots for the forecast up to 72 hours forecasts as shown in figure 4 .

All the 15 cyclones considered for this study made landfall within the forecast period of 72 hours, except cyclone number 6, 9, 12 and 13 of table 2. For instance, cyclone number 6 persisted for a longer period and made landfall after 216 hours. As the model is presumed to be valid for the forecast up to 72 hours, result beyond 72 hours forecast is not included in this paper. However, operationally the forecast can be updated at 6 hourly/12 hourly intervals on the basis of latest inputs (observations) till the landfall takes place.

\subsection{SCIP versus empirical model}

Figure 5 shows an inter-comparison of the Average Absolute Errors (AAEs) between SCIP and the empirical model proposed by Roy Bhowmik et al (2007). Inter-comparison reveals that there is significant improvement at the forecast hours 12 , 24, 60 and 72. The errors are reduced by 3 knots, 2 knots, 3 knots and 7 knots at 12, 24, 60 and 72 hours respectively. Surprisingly, the empirical model is found to be marginally better at 36 hours and 48 hours forecast. For the purpose of comparison we also compute Relative Errors (RE) index. The $\mathrm{RE}$ is defined as:

$$
\mathrm{RE}=100 \times \frac{\left(\mathrm{AAE}_{\mathrm{SCIP}}-\mathrm{AAE}_{\mathrm{Empirical}}\right)}{\mathrm{AAE}_{\text {Empirical }}} .
$$

Figure 6 shows that the $\mathrm{RE}$ is negative for forecast hours 12, 24, 60 and 72. AAE of SCIP model is reduced by $18-42 \%$ for all forecast hours except for 36 and 48 hours where it is slightly increased by about 4-7\%. Maximum improvement of error $(42 \%)$ is noticed at the 12-hour forecast. An improvement of $34 \%$ occurred at 72 hours forecast, $23 \%$ at 24 hours forecast and $18 \%$ at 60 hours forecast. These results have distinctly established that the SCIP model is superior to the earlier proposed empirical model (Roy Bhowmik et al 2007) for the Bay of Bengal.

\section{Concluding remarks}

For operational practices, there is a growing demand for accurate prediction of tropical cyclone 
intensity. The present paper describes a statistical cyclone intensity prediction model for the Bay of Bengal for the forecast at 12-hour interval valid up to 72 hours. The model is developed using multiple linear regression technique with eight predictors. The model parameters are selected based on the sample database of 62 cyclones occurred during the period 1981 to 2000 . The eight predictors selected are: initial storm intensity, intensity changes during last 12 hours, storm motion speed, initial storm latitude position, vertical wind shear averaged along storm track, vorticity at $850 \mathrm{hPa}$, divergence at $200 \mathrm{hPa}$ and sea surface temperature. The performance of the model is tested using the dependent samples of 62 cyclones as well as the independent sample of 15 cyclones. The performance of the model is found to be comparable with other statistical cyclone intensity prediction models (Jarvinen and Neumann 1979; DeMaria and Kaplan 1994, 1999; Fitzptrick 1997; Hobgood 1998; Baik et al 1998). The model is superior to the empirical model previously proposed by Roy Bhowmik et al (2007). The model appears to be promising for operational applications in the Bay of Bengal. Though the present study is based on reanalysis data, in the near future more realistic forecasts fields are expected with the availability of dense and good quality observations and sophisticated high resolution NWP models. We also intend to improve the model further by replacing SST parameters by SST anomalies. The model with the use of better model forecast fields is expected to be useful for operational application in conjunction with the latest NWP models such as HWRF.

\section{Acknowledgements}

The authors are grateful to the Director General of Meteorology, India Meteorological Department, New Delhi for providing all the facilities to carry out this research work. Authors acknowledge the use of ECMWF and NCEP data in this research work. Authors are grateful to the anonymous reviewers for their valuable comments to improve the quality of the paper.

\section{References}

Baik J J and Hwang H S 1998 Tropical cyclone intensity prediction using regression method and neural network; J. Meteor. Soc. Japan 76 711-717.

Chu J H, Sampson C R, Levine A S and Fukuda E 2002 The Joint Typhoon Warning Center Tropical Cyclone BestTracks 1945-2000; NRL Reference No. NRL/MR/754002-16.

DeMaria M and Kaplan J 1994 A Statistical Hurricane Intensity Prediction Scheme (SHIPS) for the Atlantic basin; Wea. Forecasting 9 209-220.

DeMaria M and Kaplan J 1999 An updated Statistical Hurricane Intensity Prediction Scheme (SHIPS) for the Atlantic and east North Pacific basins; Wea. Forecasting $14326-337$.

Emanuel K A 1999 Thermodynamic control of hurricane intensity; Nature 401 665-669.

Elsberry R L, Lambert T D B and Boothe M A 2007 Accuracy of Atlantic and eastern North Pacific tropical cyclone intensity forecast guidance; Wea. Forecasting $\mathbf{2 2}$ 747-762.

Fitzpatrick P J 1997 Understanding and forecasting tropical cyclone intensity change with Typhoon Intensity Prediction Scheme (TIPS); Wea. Forecasting 12 826-846.

Geisler J E 1970 Linear theory on response of a two layer ocean to a moving hurricane; Geophys. Fluid Dyn. 1 249-272.

Hobgood J S 1998 The effects of climatology and persistence variables on the intensities of Tropical cyclone over Eastern North Pacific Ocean; Wea. Forecasting 13 632-639.

Houze R A, Chen S S, Smull B F, Lee W C and Bell M M 2007 Hurricane intensity and eyewall replacement; Science 315 1235-1238.

Jarvinen B R and Neumann C J 1979 Statistical forecast of tropical cyclone intensity; NOAA Tech. Memo. NWS NHC-10, $22 \mathrm{pp}$

Kalsi S R 2005 Orissa super cyclone - A Synopsis; Mausam 57 1-20.

Kaplan J and DeMaria M 2003 Large scale characteristics of rapidly intensifying Tropical Cyclones in the North Atlantic Ocean; Wea. Forecasting 18 1093-1108.

Reynolds R W, Rayner N A, Smith T M, Stokes D C and Wang W 2002 An improved in situ and satellite SST analysis for climate; J. Climate 15 1609-1625.

Roy Bhowmik S K, Kotal S D and Kalsi S R 2007 An empirical model for predicting intensity of tropical cyclone over the Bay of Bengal; Nat. Hazards $\mathbf{4 1}$ 447-455.

Schade L R and Emanuel K A 1999 The Ocean's effect on the intensity of Tropical Cyclones: Results from a simple coupled atmosphere-ocean model; J. Atmos. Sci. 56 642-651. 